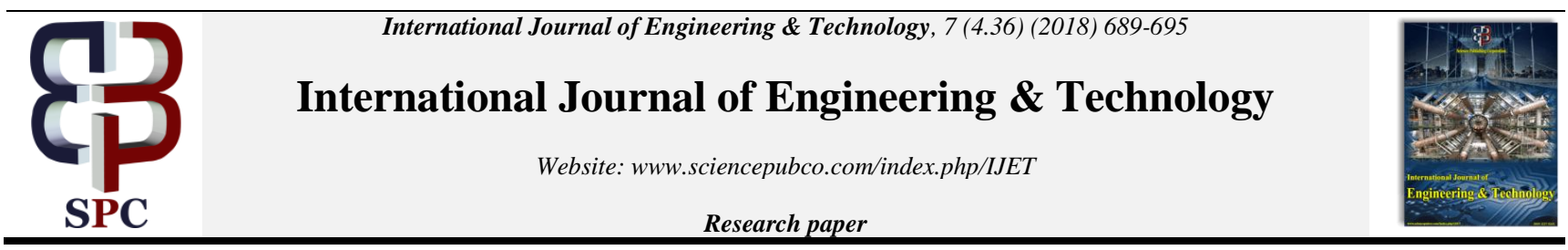

\title{
A Survey on Unimodal, Multimodal Biometrics and Its Fusion Techniques
}

\author{
A.S. Raju ${ }^{*}$, V. Udayashankara ${ }^{2}$ \\ ${ }^{1}$ Research Scholar, Department of Electronics \& Instrumentation Engineering, Sri Jayachamarajendra College of Engineering, Mysore, India. \\ ${ }^{2}$ Professor, Department of Instrumentation Technology, Sri Jayachamarajendra College of Engineering, Mysore, India.
}

\begin{abstract}
Presently, a variety of biometric modalities are applied to perform human identification or user verification. Unimodal biometric systems (UBS) is a technique which guarantees authentication information by processing distinctive characteristic sequences and these are fetched out from individuals. However, the performance of unimodal biometric systems restricted in terms of susceptibility to spoof attacks, non-universality, large intra-user variations, and noise in sensed data. The Multimodal biometric systems defeat various limitations of unimodal biometric systems as the sources of different biometrics typically compensate for the inherent limitations of one another. The objective of this article is to analyze various methods of information fusion for biometrics, and summarize, to conclude with direction on future research proficiency in a multimodal biometric system using ECG, Fingerprint and Face features. This paper is furnished as a ready reckoner for those researchers, who wish to persue their work in the area of biometrics.
\end{abstract}

Keywords: Authentication, verification, unimodal, multi-modal, face, finger, ECG, biometrics.

\section{Introduction}

Client confirmation is a standout amongst the most huge and critical parts of controlling unapproved access to a framework.

The word biometric in Greek named as profiles (life) and metrons (measure).

Biometrics is an innovation of utilizing one of a kind attributes of people as estimation units for confirming them, in light of physiological and social qualities of individuals, and of utilizing natural attributes in confirmation through mechanized devices [1].

In short biometric is where PC approves the client has an authentic case to get to the framework [2].

The term biometrics is a programmed validation or recognizable proof framework which utilizes individual conduct or physiological highlights.

Human organic properties, for example, fingerprints, iris, voice, face, and hand geometry characteristics utilized in biometrics innovation. Programmed and exact character approval is winding up increasingly critical in different parts of our regular daily existences, for example, in access control, monetary exchanges, voyaging, medicinal services and numerous others.

Conventional strategies for programmed uniqueness recognizable proof or acknowledgment comprise of Stick numbers, passwords, tokens and personality (ID) cards.

In spite of the wide sending of such procedures, the sort of confirmation is either element based or information based which raises genuine worries with respect to the danger of wholesale fraud. Biometric modalities are hard to phony or take, when contrasted with passwords or Stick numbers. Biometric validation utilizes unmistakable physical qualities, so it isn't fundamental to people to convey any extra character authentication.

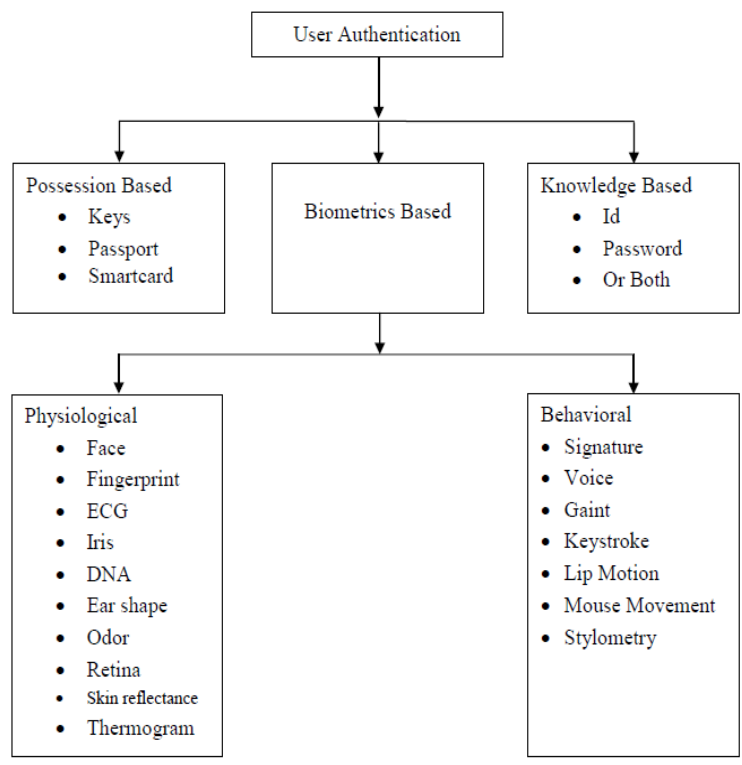

Figure 1: Ontology of authentication modes

Figure 1 illustrates ontology of different types of authentication approaches, with biometric traits. Biometric Identification is a One-to-Many comparing of the captured biometric trait versus complete stacked patterns to verify an individual's characteristics. This paper describes the survey on recent developments in multimodality biometrics and its fusion techniques. Section 2 describes general overview and architecture of biometric system Section 3 describes literature survey on unimodal biometrics specific to ECG, Face and Fingerprint. Section 4 describes 
multimodal biometrics Section 5 briefly explains integration techniques Section 6 describes literature survey on multimodal biometrics and the conclusion and discussion is in section 7 .

\section{Biometric system}

Verification of individuals is a major significant concern in security. A biometric system is pattern recognition systems that identify a person based on definite physiological or behavioral features. Biometric systems established with a single source of information are known as unimodal biometric systems. Several unimodal biometric systems built with either one of physiological or behavioral characteristics. Biometric Verification is a one-toone comparing of captured biometric attribute versus the modal of the individual claims to be, the individuality claim is consented as "true" if the scale of resemblance is adequately high, as "fraud" otherwise. For instance, access to a bank account or restricted areas the biometrics retinal or fingerprint scans could be applied [3].

Four major elements of various biometric systems share a common architecture (Figure 2), which is composed of four major elements:

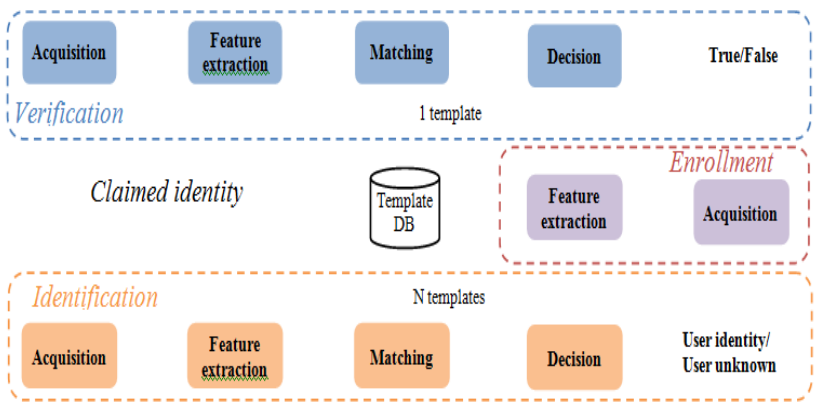

Figure 2: General architecture of a biometric system [3]

Acquisition: Biometrics sensor hardware is the primary module, which captures biometric data from individuals. For example, camera sensor is to capture face and iris images, a scanner for fingerprints, microphones for voice data etc. [3].

Feature extraction: The captured biometric information is preprocessed to eliminate any supplementary defects or noises and is further processed for feature extraction procedure to pull out biometric features those are preferable should depict uniqueness of an individual.

Matching component: In this module feature vectors from an unknown subject are evaluated against stored database results as the corresponding score representing the degree of resemblance between a pair of biometrics data. For the same subjects features the resulting score should be high and low for different ones.

Decision module: Here the individual's identity is recognized that is a claimed identity is rejected/accepted with reference to the resultant similarity score. In general, the final assessment is estimated by evaluating the similarity score to the constant threshold and is chosen according to the deliberation of the degree of security requisites of the application [3].

In past researchers have been studied and experimented on individual biometric (unimodal) attributes such as Voice, Fingerprint, Face, Iris, Signature, and ECG for identification and authentication. The performance of the system cannot be guaranteed for the measurement of single modality, due to limitations of unimodal biometrics system. Limitations of unimodal biometric systems[4]are related to variable environmental conditions (i.e. noisy input data, changes in illumination), intra-class variation, non-universality, lack of distinctiveness, spoof attack, etc., on the other hand, single biometric feature is inadequate for authentication in all situations. Constraints of UBS in their performance with respect to characteristics such as Permanence, Universality, Acceptability, Uniqueness, and Collectability etc. are described in Table 1. In order to defeat such restrictions, multimodal biometric systems are introduced. Methods for integrating biometric attributes or combined matching decisions have to pay more attention to the researchers by fusing biometric characteristics or traits from various sources of information to establish multimodal biometric identity or recognition or verification systems [4].

Table 1: Unimodal Biometrics Performance Comparison [Jain et al, 2004][5]

\begin{tabular}{|c|r|r|r|r|r|r|r|}
\hline Biometrics & $\begin{array}{c}\text { Uniquen } \\
\text { ess }\end{array}$ & Universality & Collectability & Permanence & Acceptability & Circumvention & $\begin{array}{c}\text { Environmental } \\
\text { Impact }\end{array}$ \\
\hline Face & $\downarrow$ & $\uparrow$ & $\uparrow$ & $\uparrow$ & $\uparrow$ & $\downarrow$ & $\uparrow$ \\
\hline $\begin{array}{c}\text { Keystroke } \\
\text { Dynamics }\end{array}$ & $\downarrow$ & $\downarrow$ & $\uparrow$ & $\downarrow$ & $\uparrow$ & $\uparrow$ & $\uparrow$ \\
\hline Fingerprint & $\uparrow$ & $\uparrow$ & $\uparrow$ & $\uparrow$ & $\uparrow$ & $\uparrow$ & $\uparrow$ \\
\hline Signature & $\downarrow$ & $\downarrow$ & $\uparrow$ & $\downarrow$ & $\uparrow$ & $\downarrow$ & $\uparrow$ \\
\hline Hand Vein & $\uparrow$ & $\uparrow$ & $\uparrow$ & $\uparrow$ & $\uparrow$ & $\uparrow$ & $\downarrow$ \\
\hline $\begin{array}{c}\text { Hand } \\
\text { Geometry }\end{array}$ & $\uparrow$ & $\uparrow$ & $\uparrow$ & $\uparrow$ & $\uparrow$ & $\uparrow$ & $\uparrow$ \\
\hline Retina & $\uparrow$ & $\uparrow$ & $\downarrow$ & $\uparrow$ & $\downarrow$ & $\uparrow$ & $\downarrow$ \\
\hline Iris & $\uparrow$ & $\uparrow$ & $\uparrow$ & $\uparrow$ & $\downarrow$ & $\uparrow$ & $\downarrow$ \\
\hline $\begin{array}{c}\text { Facial } \\
\text { Thermogram }\end{array}$ & $\uparrow$ & $\uparrow$ & $\uparrow$ & $\downarrow$ & $\uparrow$ & $\uparrow$ & $\uparrow$ \\
\hline DNA & $\uparrow$ & $\uparrow$ & $\downarrow$ & $\uparrow$ & $\downarrow$ & $\downarrow$ & $\downarrow$ \\
\hline Voice & $\downarrow$ & $\uparrow$ & $\uparrow$ & $\downarrow$ & $\uparrow$ & $\downarrow$ & $\uparrow$ \\
\hline ECG & $\uparrow$ & $\uparrow$ & $\uparrow$ & $\uparrow$ & $\uparrow$ & $\uparrow$ & $\downarrow$ \\
\hline
\end{tabular}

\section{A Survey: unimodal biometrics}

In our work ECG, Fingerprint, Face unimodal biometric traits are selected, by choosing ECG as a Biometric, offers high accuracy and proof of individual existence and liveliness detection with real time biometric cues which are spoof proof.

The ECG provides the missing biometric data to an un-obtrusive biometric namely Face and Fingerprint when all are combined together which are known for least obtrusive biometrics.

It shown, fusing ECG signal with the fingerprint-face biometrics, a consistent credential of an individual is created. Thus, fusion of ECG and fingerprint-face will enhance the biometric authentication performance parameters and the accuracy of the system is improved, and by integrating the ECG with other Biometrics also increase the discriminative information of biometric trait.

\subsection{Electrocardiogram (ECG) Biometric}

ECG is one of the more up to date increases to the biometric network. The electrocardiogram flag is the sign of the electrical action of the cardiovascular muscles, by customary constrictions and relaxations of heart muscles as for time [6]. There have been numerous investigations on indispensable highlights of ECG with the proof in the $\mathrm{P}, \mathrm{Q}, \mathrm{R}, \mathrm{S}, \mathrm{T}$ wave signals. The people demonstrate the heterogeneous in ECG designs, because of adjustment in the utilization of this flag for distinguishing proof and validation. We will quickly clarify the component extraction systems of a few techniques from the early work to the present and report the execution accomplished by them in the accompanying segment. Biel et al.[7] proposes a fiducial based technique utilizing ECG accounts from 20 subjects. The removed highlights are the neighborhood qualities of the QRS complex, T wave and $\mathrm{P}$ wave. The best execution that was accomplished by consolidating 10 unique highlights was accounted for with acknowledgment the rate of $100 \%$. 
Kyoso et al. [8] proposed a fiducial technique utilizing four highlights, the span of PQRS interim, PQ\& QT terms. Most astounding execution announced with an acknowledgment rate of94\% utilizing the QRS and QT interims of nine subjects.

Shen et al. [9] proposed an Electrocardiogram biometric framework. In this examination work format and choice counterfeit neural system, characterization techniques are tried to create individual check framework with fiducial highlights which are identify with the QRS interim. The exploratory outcomes recorded $95 \%$ and $80 \%$ of precision as right character check with layout coordinating and DBNN separately. Combination of two methods gives $100 \%$ acknowledgment rate.

Kim et al. [10] proposed a fiducial technique by utilizing time areas of PQRST ECG waveform. Fourier combination technique is utilized to reproduction ECG data.QRS interim, QT and RT interim on there casing ECG in both rest and physical state were ascertained. They tried their technique on 10 people.

Chan et al. [11] additionally propose a non-fiducial technique which uses the detail coefficients of the DWT of PQRST buildings for the highlights and a proposed wavelet based separation measure for grouping. Fifty subject's ECG information is caught in three distinct information recording sessions. First session information is utilized as framework enrolment i.e., as preparing information, and staying two sessions information is utilized as experiments. Three quantitative estimates utilized as characterization: specifically connection coefficient, percent leftover distinction and separation measure dependent on wavelet change. The most elevated execution detailed was $89 \%$ utilizing the wavelet remove measure.

Agrafioti et al. [12] strategy utilizing the autocorrelation the wellspring of discriminative information in a populace, to kill the requirement for fiducial focuses recognizable proof. The auto associated ECG signs, DCT or LDA is connected for dimensionality decrease. The best execution announced is an EER of under $1 \%$ tried on 27 subjects.

Safie et al. [13]propose another fiducial-based technique that uses the beat dynamic proportion (Standard) calculation for highlight extraction rather than traditional fleeting and abundancy highlights. To start with, the individual pulses are recognized and after that the Standard component vector is processed. Their assessments were performed on 112 people and announced an EER of $9.89 \%$ on sound subjects.

Zhao et al. [14] proposed a non-fiducial system on outfit observational mode disintegration (EEMD). They initially take out the clamor of the ECG flag utilizing wavelet disintegration and afterward they extricate the individual pulses. Moreover, heartbeat is standardization and quality estimation are performed to take out the impacts pulse inconstancy. At that point the ECG pulses are decayed into a few characteristic mode capacities (IMFs). The PCA-instrument diminish dimensionality of highlight space parameter and the K-closest neighbors calculation as the classifier device. The framework accomplished an ID precision of $95 \%$ for 90subjects.

Odinaka et al.[15] propose the time recurrence data of pulses as the component parameter and with an element determination method for dimensionality decrease and upgrade of its execution. Calculation executed in this work was assessed on a database containing chronicles from 269 subjects and report an EER of $5.58 \%$

\subsection{Face}

The examination work is continuous on breaking down and acknowledgment of human face pictures. The benefit of breaking down face pictures lies in nonintrusive procedure of the getting methodology and, relies upon the calculation. In which pictures are handled in a sensible time. The confined highlights of face, for example, nose, eyes or worldwide morphology [3] are utilized in examination official data. Then again, brightening natura components influence the execution of the particular frameworks. Also, wistful articulations and maturing exasperate the acknowledgment essentially, influencing the precision of the applications [16]

R.Senthilkumar et al.[17] proposed the time required for face acknowledgment biometric framework. In this work include extraction is performed by surface based Haralick extraction method, the face characterization is finished utilizing ANFIS classifier. Subsequently this procedure is known as HANFIS. The outcomes acquired in this work unmistakably demonstrate the exactness very nearly $90 \%-100 \%$ face acknowledgment which is quicker than existing different methodologies.

K.Raju et al.[18] gives the points of interest of face recognizable proof in the field of picture preparing errand. In spite of the fact that one of its benefits is that the individual can without much of a stretch be perceived by the group through face acknowledgment, however it has various issues that need to overcome, for example, outward appearances, maturing, impediment and so on. Face acknowledgment strategy can just been tertained on the off chance that it can make out the face effectively. Worldwide highlights (DWT, PCA) and point-based features(Harris corner, SURF) both are estimated to make a combination based framework for programmed confront acknowledgment. Exactness, affectability, and accuracy are the execution appraisal parameters are assessed. The combination based methodology gives 99.4 percent precision. Amrutha Bhat et al.[19] depicts the humans have always had the innate capability to recognize and distinguish between faces; recently computers have exposed an equal ability to recognize and discriminate the human faces. It is a method of identifying a person by comparing live capture image data with the stored documentation. The comparison is done on the recognition rate of Local Binary Pattern (LBP) with Laplacian of Gaussian (LoG) method, PCA and Local Binary Pattern methods. The Laplacian of Gaussian (LoG) method is used for edge detection and for feature extraction LBP and PCA methods are used. The SVM Classifier is used to classify the images. The LBP with LoG gives better recognition rate than the PCA and LBP methods.

Ancy Anna Varghese et al. [20] proposed aging is defined as a biological process of growing older. Aging inference deals with the prediction of specific age or age group from the face. Aging face recognition has numerous applications in the real world including missing children finding, passport verification etc. Aging rate for different persons is dissimilar because of its great dependence on intrinsic and extrinsic factors. Extrinsic factors include eating habits, living style, working condition etc and intrinsic factors include a change in shape and size of the face. Intra user dissimilarity is a practical term used to describe the changes happening to the person's outer shell due to aging. This work presents a novel and effective method for automatic age estimation. Aging face recognition helps in identifying the culprit when the system is skilled using the dataset of the culprit and the personal information gathered helps in understanding the person. Azad Abdullah Ameen et al.[21] applied DWT for facial feature extraction and feature reduction using LBP algorithm. It is evaluated in two different ways: DWT is used on LBP features, also DWT is applied twice on the original image, LBP features. The outcomes are equated to the results obtained on without utilizing DWT, this brings out in reduction base one wavelet achieves the same or improvement in recognition rate. The experiment is conducted on the Cambridge ORL Face database. D. Sharadamani et al.[22] illustrate the promising impression of the smart city has paid mind in the research field of urban development. One of the disputes of the smart city is how to realize the data collected by the sensor and make a decision. The face detection plays a key role in our social communication in spinning over the personality and emotions. The human talent to recognize faces is notable but the face is a complicated multidimensional image for development of competent model. Here, a new unique real-time face recognition system is proposed by combining local orientation gradient XOR patterns and Local 
gradient XOR patterns. This new method consists of three steps 1) local gradient XOR patterns are calculated 2) Local Oriented Gradient XOR patterns are calculated and 3) feature vector can be constructed by fusing histograms of LGXORP \& LOGXORP.

Hamayun A. Khan et al.[23] proposed a face biometric system based on feature fusion and classifier ensemble method in the classifier space. In feature space, feature extraction is performed by using the Histogram of Oriented Gradient (HOG) and DWT algorithm. For classification PCA method is used. To improve performance various parameters of HOG features, DWT and the classification ensemble are used. AT\&T (ORL) and Yale benchmark face databases are used, they have recorded the recognition rate of $99.78 \%$ and $97.72 \%$.

Saloni Dwivedi et al. [24] presented a real time face recognition algorithm execution and its successive consequences on several validation datasets of live images. Face detection is performed using Voila-Jones method. Face recognition is carried out by eigen faces and Euclidean faces algorithms. The performance evaluation is carried out on four subjects, highest recognition rate recorded as $90 \%$.

\subsection{Finger print}

This is a standout amongst the most regularly utilized biometrics. The prior fingerprints are obtained on paper utilizing ink-marks which are utilized in legal sciences for the acknowledgment of offenders. Be that as it may, fingerprints are caught by utilizing ultrasonic and optical sensors. which measure the valleys, islands and edges in a unique finger impression.

Rupali S. Patilet al. [25] proposed unique mark biometric utilizing surface DCT and highlight calculations. The corpus of five hundred unique mark tests caught from hundred people are utilized for check and confirmation reason. The acknowledgment rate is recorded as $91.75 \%$.

Bikash Debnath et al. [26] delineates a nano-scale coherent circuit can be gotten effectively through QCA gadget. The unique mark can be arranged as a one of a kind element for individual ID. Unique mark acknowledgment is done through biometrics, along these lines it is a basic piece of client verification. Irreversible innovation seeing a few troubles like higher dispersed warmth. Along these lines, reversible rationale is basic where dispersal of warmth will be relatively inconsequential. A reversible circuit for unique mark authenticator utilizing Feynman door has been anticipated and executed with QCA. Both the nonexistent qualities and the reproduction results are in line which gives a valid justification for the validity of things to come circuit's outline.

Prashant Bhaskarrao Patil et al. [27] anticipated joined Particulars based coordinating framework as unique mark biometric. They introduced particulars focuses and introduction from a picture framework could produce Joint Details. The investigations are completed from FVC_2002 database.
Table 0.1: Summary of Fusion Techniques in Biometrics

\begin{tabular}{|c|c|c|c|c|c|}
\hline $\begin{array}{l}\mathrm{Sl} \\
\mathrm{N}\end{array}$ & $\begin{array}{c}\text { First } \\
\text { Author }\end{array}$ & Year & $\begin{array}{l}\text { Fusion } \\
\text { method }\end{array}$ & Modality & Biometric Sources \\
\hline 1 & F. Yang[28] & 2005 & SLF & Unimodal & Face \\
\hline 2 & $\begin{array}{l}\text { Y.L. Zhang et al } \\
{[29]}\end{array}$ & 2005 & SLF & Unimodal & Fingerprint \\
\hline 3 & $\begin{array}{l}\text { G.L. Marcialis et al } \\
{[30]}\end{array}$ & 2009 & ScLF & Multimodal & Faces and Fingerprints \\
\hline 4 & $\begin{array}{l}\text { M. Vatsa et al } \\
{[31]}\end{array}$ & 2009 & ScLF & Unimodal & Fingerprints \\
\hline 5 & $\begin{array}{l}\text { L. Nanni et al } \\
\text { [32] }\end{array}$ & 2009 & SCLF & Unimodal & Fingerprint \\
\hline 6 & $\begin{array}{l}\text { M. Vatsa et al } \\
{[33]}\end{array}$ & 2010 & ScLF & Unimodal & Face \\
\hline 7 & $\begin{array}{l}\text { A. Kumar et al } \\
\text { [34] }\end{array}$ & 2011 & DLF & Unimodal & Palmprints \\
\hline 8 & M.M. Monwar et al [35] & 2011 & DLF & $\begin{array}{l}\text { Multimodal } \\
\end{array}$ & Ear, Iris, and Face \\
\hline 9 & $\begin{array}{l}\text { A. Nagar et al } \\
\text { [36] }\end{array}$ & 2012 & FLF & Multimodal & fingerprint, Iris, and Face \\
\hline 10 & $\begin{array}{l}\text { J. Yang et al } \\
{[37]}\end{array}$ & 2012 & FLF & Multimodal & Fingerprint and Finger-vein \\
\hline 11 & $\begin{array}{l}\text { Sara Zokaee et al } \\
{[38]}\end{array}$ & 2012 & ScLF & Multimodal & $\begin{array}{l}\text { Electrocardiogram and } \\
\text { Palmprint }\end{array}$ \\
\hline 12 & $\begin{array}{l}\text { C.H. Chan et al } \\
{[39]}\end{array}$ & 2013 & FLF & Unimodal & Face \\
\hline 13 & $\begin{array}{l}\text { Z. Huang et al } \\
{[40]}\end{array}$ & 2013 & FLF & Multimodal & Face and ear \\
\hline 14 & $\begin{array}{c}\text { G. Goswami et al } \\
{[41]}\end{array}$ & 2015 & FLF & Multimodal & Multimodal \\
\hline 15 & $\begin{array}{c}\text { N. Poh et al } \\
{[42]}\end{array}$ & 2013 & ScLF & Multimodal & Faces and speech \\
\hline 16 & $\begin{array}{l}\text { H.S. Bhatt et al } \\
\text { [43] }\end{array}$ & 2014 & DLF & - & Video face \\
\hline 17 & $\begin{array}{l}\text { Z. Zhang et al } \\
{[44]}\end{array}$ & 2014 & SLF & Unimodal & Face \\
\hline 18 & $\begin{array}{l}\text { M. Gogoi et al } \\
\text { [45] }\end{array}$ & 2014 & DLF & - & Fingerprint and Iris \\
\hline 19 & $\begin{array}{l}\text { C. Li, J. Hu et al } \\
{[46]}\end{array}$ & 2015 & DLF & - & Fingerprints \\
\hline 20 & $\begin{array}{l}\text { H. Mehrotra et al } \\
\text { [47] }\end{array}$ & 2015 & SCLF & Multimodal & fingerprint and Iris \\
\hline 21 & $\begin{array}{l}\text { M. Hanmandlu et al } \\
{[48]}\end{array}$ & 2015 & SCLF & Multimodal & IR Face, Ear and Iris \\
\hline 22 & $\begin{array}{l}\text { K. Nguyen et al } \\
{[49]}\end{array}$ & 2015 & SCLF & Multimodal & Faces, Fingerprint and ris \\
\hline 23 & $\begin{array}{l}\text { S. Bharadiwaj et al } \\
\text { [50] }\end{array}$ & 2015 & SCLF & Multimodal & Face, Fingerprint and rris \\
\hline 24 & $\begin{array}{c}\text { N. Celiket al } \\
{[51]}\end{array}$ & 2015 & DLF & Multimodal & Fingerprint and Face \\
\hline 25 & $\begin{array}{c}\begin{array}{c}\text { Manjunathswwamy B E et al } \\
{[52]}\end{array} \\
\end{array}$ & 2016 & SCLF & Multimodal & $\begin{array}{l}\text { Iris, Finger vein, Palm printand } \\
\text { Face }\end{array}$ \\
\hline 26 & $\begin{array}{l}\text { Afshan Ashrafet al } \\
\text { [53] }\end{array}$ & 2017 & ScLF & Multimodal & $\begin{array}{l}\text { Retina, Finger vein and Finger } \\
\text { print }\end{array}$ \\
\hline
\end{tabular}

\subsection{Multimodal biometrics}

Sara Zokaee et al[38]are proposed biometrics for permutation features of Palmprint and ECG biometrics. Mel-Frequency Cepstral Co-efficients (MFCCs) and Principal Component Analysis(PCA) algorithms extract features of ECG Palm print respectively. The experiments are carried out on standard MIT$\mathrm{BIH}$ and POLYU corpus. Furthermore, to achieve better performance, author collected Holter ECG recordings captured 50 male and female subjects aging from between 18 and 45. The recognition rate of $94.7 \%$ is recorded from the experiments.

Manjunathswamy B E et al.[52]were developed a MMBS using ECG and fingerprin biometric traits. ECG signals are captured by using Biopac MP35 from various subjects. The similarity scores are generated for the ECG features includes amplitude, angle and interval features. For fingerprint minutia features are estimated by removing H_breaks and spikes in the thinned binary pictures. They have recorded that for ECG, FRR and FAR as $9.52 \%$ and $2.38 \%$ respectively, FRR and FAR for fingerprint $5.55 \%$ and $7.77 \%$ respectively and furthermore with fusion of ECG and fingerprint FRR and FAR are $0 \%$ and $2.5 \%$ respectively.

Afshan Ashraf et al. [53] defines a multi-modal scheme for verification based biometric fusion of finger vein, fingerprint and retina recognition and proposed feature removal in retina recognition model by using SIFT and MINUTIA feature extract at work in different levels. The projected work adds three biometric traits of a user i.e. retina, fingerprint and finger veins by an implemented software, presently these are pre-processed and combined together for score level fusion technique is used. Here retina is selected as a biometric trait because of retina has a good vessel pattern making and it is a good verifying approach as compared to other biometric traits. Security is found in the system 
by multi-modal biometric it is a combination of retina, finger vein and fingerprint. Feature extraction approach and cryptography is used to achieve higher security. Feature extraction is done with the help of MINUTIA and SIFT algorithm which are then classified using Deep Neural Network (DNN).

Ruxin Wang et al.[54] proposed a system fingerprint biometric system with neural network approach. For the NIST-DB4 database as a four-class problem, the writer has achieved accuracy of $93.1 \%$ and with 3 hidden layers $1.8 \%$ rejection. Experimented a novel approach using 2 categorization probabilities for fuzzy taxonomy to improve the classification problem. With adjusting the probability threshold, they achieved accurateness of classification is $96.1 \%, 97.2 \%$, and $98.0 \%$.

Stephane Kouamo et al.[55]developed a neural network-based fingerprint biometric system for E-learning.

For training a multilayer perceptron backpropagation algorithm is used. With the NIST special DB 4 and a local DB the results of experimentation shows that a proposed method gives better results in certain cases.

Ujwalla Gawande et al.[56] this research work presents on MMBS and its issue and challenges. They implemented algorithms for addressing the issues as well as challenges of fingerprint plus iris biometric system. CASIA databank used to implement the said system.

They have observed the accuracy of 89 percent with 2 percent FAR and 11 percent FRR by using novel block sum feature set. Pavol Marak et al. [57] were developed a novel algorithm for fingerprint recognition system using ANN. The results with FMR2002 DB3A database, the accuracy recorded 67 percent of classified subjects for the decision.

They have observed the EER point of 33 percent which indicates the difference of FMR and FNMR, it indicates less ideal with Cross -Match database.

Recent works on various multi-modal biometrics with its Databases (DB), Biometric sources, methodology or algorithm used to implement, system performance of biometric system is summarized in Table2.2.

Table 0.2: Recent Works on Various Multi-Modal Biometrics

\begin{tabular}{|c|c|c|c|c|c|c|}
\hline First Author & year & $\begin{array}{l}\text { Biometric } \\
\text { Corpus }\end{array}$ & $\begin{array}{l}\text { No. of } \\
\text { subjects }\end{array}$ & $\begin{array}{l}\text { Biometric } \\
\text { Traits }\end{array}$ & $\begin{array}{c}\text { Method } \\
\text { used }\end{array}$ & $\begin{array}{l}\text { Performance of Classification in } \\
\text { Percentage }\end{array}$ \\
\hline $\begin{array}{l}\text { Xu } \\
\text { Xiaona [58] }\end{array}$ & 2009 & USTBcorpus & 79 & $\begin{array}{l}\text { 2D and 3D } \\
\text { Face and } \\
\text { Ear }\end{array}$ & $\begin{array}{l}\mathrm{K} \text { KPAA } \\
\text { KFDA }\end{array}$ & $\begin{array}{l}\text { Using method KPCA } 4.52 \% \text { and } \\
\text { KFDA90.84\% }\end{array}$ \\
\hline $\begin{array}{l}\text { MH.Mahoor } \\
{[59]}\end{array}$ & 2009 & $\begin{array}{l}\text { Database from } \\
\text { West Virginia } \\
\text { University }\end{array}$ & 402 & $\begin{array}{l}\text { 2D and 3D } \\
\text { Face and } \\
\text { Ear } \\
\text { respectively }\end{array}$ & $\begin{array}{l}\text { Weighted } \\
\text { sum } \\
\text { Technique }\end{array}$ & $\begin{array}{l}\text { EER- } 0.1 \% \% \\
\text { FAR-0.04\%, } \\
\text { Rank one identity } 100 \%\end{array}$ \\
\hline Darwish[60] & 2009 & Yale, MIT & $\begin{array}{l}\text { MTT- } \\
\text { 40ORL- } \\
15 \text { YALE- } \\
10\end{array}$ & Face, Ear & $\begin{array}{l}\text { Principal } \\
\text { component } \\
\text { analysis }\end{array}$ & $\begin{array}{l}92.24 \% \text { of accuracy } 10 \% \text { of FAR } \\
6.1 \% \text { of FRR }\end{array}$ \\
\hline MIRazzak [61] & 2010 & CAIRO & 35 & 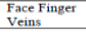 & CSLDA & $\begin{array}{l}\text { FAR } 0.05 \% \\
\text { GAR } 91.4 \%\end{array}$ \\
\hline MdSoltane [62] & 2010 & $\begin{array}{l}\text { AVI } \\
\text { resolution640 } \\
\text { x 480UYVY }\end{array}$ & 30 & $\begin{array}{l}\text { Face and } \\
\text { Voice }\end{array}$ & $\begin{array}{l}\text { Gaussian } \\
\text { mixture } \\
\text { model }\end{array}$ & $\begin{array}{l}\text { EER: } \\
\text { Face-0.44935. } \\
\text { Speech-0.00269.Bimodal-0.08728 }\end{array}$ \\
\hline PDalka [63] & 2010 & $\begin{array}{l}\text { In-house face } \\
\text { corpus } \\
\text { captured from } \\
\text { web camera }\end{array}$ & 176 & $\begin{array}{l}\text { Lip } \\
\text { movements } \\
\text { and } \\
\text { Gestures }\end{array}$ & ANN & Recognition Rate93.7\% \\
\hline LinlinShen $[64]$ & 2011 & AR PolyU & $\begin{array}{l}\text { AR } \\
\text { 1190lyU : } \\
\text { 386Palms }\end{array}$ & $\begin{array}{l}\text { Face Palm } \\
\text { print }\end{array}$ & FPCODE & FLF 91.52\%DLF 91.63\% \\
\hline M. Kawulok[65] & 2012 & FERETAR & 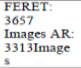 & $\begin{array}{l}\text { Face and } \\
\text { Eye }\end{array}$ & \begin{tabular}{l|} 
multi-level \\
elilpe \\
detcetor with \\
SVMM with
\end{tabular} & $\begin{array}{l}\text { recognition rate } 0.5 \% \text { for FERET } \\
7.7 \% \text { for } A R\end{array}$ \\
\hline Sara Zokaec[38] & 2012 & $\begin{array}{l}\text { MIT-BUH\& } \\
\text { POLYU }\end{array}$ & $\begin{array}{l}50 \text { male } \\
\text { and female } \\
\text { subjects in } \\
\text { age } \\
\text { between } 18 \\
\text { and } 54\end{array}$ & $\begin{array}{l}\text { ECG Palm } \\
\text { print }\end{array}$ & $\begin{array}{l}\mathrm{MFCC} \text { and } \\
\mathrm{PCA}\end{array}$ & $94.7 \%$ of the detection rate \\
\hline Ruxin Wang[54] & 2014 & NIST-DB4 & $\begin{array}{l}4000 \\
\text { fingerprint } \\
\text { pictures }\end{array}$ & Fingerprint & $\begin{array}{l}\text { probabbility } \\
\text { threstold } \\
\text { and fuzzy } \\
\text { classification }\end{array}$ & $\begin{array}{l}\text { Accuracy of classification is } 96.1 \% \text {. } \\
\text { thrueshololis is } 0.55 .97 .2 \% \text { (seting threstold is } \\
0.90) \text { and } 98.0 \% \text { (setting threshold is } 0.95 \text { ) }\end{array}$ \\
\hline $\begin{array}{l}\text { Manjunathswam } \\
\text { y B E [52] }\end{array}$ & 2015 & $\begin{array}{l}\text { ECG database } \\
\text { collected from } \\
\text { Biopac MP35 }\end{array}$ & & $\begin{array}{l}\text { Fingerprint } \\
\text { and ECG }\end{array}$ & $\begin{array}{l}\text { Minutia for } \\
\text { Fingerprint } \\
\text { and }\end{array}$ & $\begin{array}{l}\text { FRR } 0 \% \\
\text { FAR } 2.5 \% \\
\end{array}$ \\
\hline Pavol Marak[57] & 2016 & $\begin{array}{l}\text { FVC testing } \\
\text { corpus from } \\
2000,2002, \\
2004 \text { and } \\
\text { fingerprint } \\
\text { samples from } \\
\text { NIST Special } \\
\text { Database 27a. }\end{array}$ & $\begin{array}{l}5851 \\
\text { fingerprint } \\
\text { images }\end{array}$ & Fingerprint & $\begin{array}{l}\text { FMR R FNMR } \\
\text { and ROC } \\
\text { indicators }\end{array}$ & 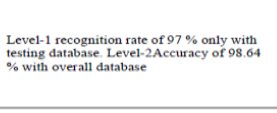 \\
\hline $\begin{array}{l}\text { Stephane } \\
\text { Kouamo [55] }\end{array}$ & 2016 & $\begin{array}{l}\text { BDAL } \\
\text { NIST }\end{array}$ & 500 & Fingerprint & $\begin{array}{l}\text { back } \\
\text { propagation } \\
\text { algorithm }\end{array}$ & $\begin{array}{l}\text { FAR ranging from } 0.6 \% \text { to } 4.8 \%, \text { FRR } \\
\text { ranging from } 1.1 \% \text { to } 5.3 \%\end{array}$ \\
\hline $\begin{array}{l}\text { Ujwalla } \\
\text { Gawande [56] }\end{array}$ & 2017 & CASIA iris & 60 & Iris & DWT & 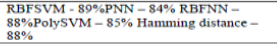 \\
\hline $\begin{array}{l}\text { Ronald Salloum } \\
{[66]}\end{array}$ & 2017 & $\begin{array}{l}\text { ECG-DE } \\
\text { MIT-BHH } \\
\text { Arthylhial } \\
\text { MIITDB). }\end{array}$ & 125 & ECG & $\begin{array}{l}\text { RNN, LSTM } \\
\text { and GRU }\end{array}$ & 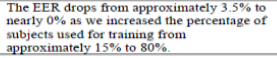 \\
\hline Raju AS [67] & 2018 & $\begin{array}{l}\text { In house } \\
\text { database of } \\
\text { Created for } \\
\text { ECG, for } \\
\text { Fingerprint } \\
\text { and Faces }\end{array}$ & so & $\begin{array}{l}\text { ECG } \\
\text { Fingerprint } \\
\text { Face }\end{array}$ & $\begin{array}{l}\text { FLF method } \\
\text { aud } \\
\text { Euctidean } \\
\text { distance }\end{array}$ & $\begin{array}{l}\text { ECG } \\
\text { ifo.8333Face: } 76.4706 \text { Fingerprint: } 73.0769 \mathrm{M} \\
\text { whtimodal: } 73.4602\end{array}$ \\
\hline
\end{tabular}

\section{Conclusion and Discussions}

This paper surveyed major mechanical point of view and esteem of the key advancement in unimodal and multimodal biometrics. We examined about general design of biometric framework and in detail biometric combination strategies. We portrayed late work in biometrics utilizing Face, Finger, and ECG. It is additionally seen that execution of multimodal biometrics conquer constraints unimodal biometrics frameworks. There are various multimodal biometric arrangements in being for confirmation of an individual anyway accumulation of appropriate modals, inclination in ideal combination level and excess in the caught highlights are few challenges in designing multimodal biometric solution that needs to be solved.

\section{References}

[1] Zhang DD, Automated biometrics: Technologies and systems, Springer Science \& Business Media, (2013).

[2] Unar JA, Seng WC \& Abbasi A, "A review of biometric technology along with trends and prospects", Pattern recognition, Vol.47, No.8, (2014), pp.2673-2688.

[3] Lumini A \& Nanni L, "Overview of the combination of biometric matchers", Information Fusion, Vol.33, (2017), pp.71-85.

[4] Raju AS \& Udayashankara V, "Biometric person authentication: A review", IEEE International Conference on Contemporary Computing and Informatics (IC3I), (2014), pp.575-580.

[5] Jain AK, Ross A \& Prabhakar S, "An Introduction to Biometric Recognition", IEEE Transactions on Circuits and Systems for Video Technology, Special Issue on Image- and Video-Based Biometrics, Vol.14, No.1, (2004), pp.4-20.

[6] Pouryayevali S, ECG biometrics: new algorithm and multimodal biometric system (Doctoral dissertation), (2015), pp.1-93.

[7] Biel L, Pettersson O, Philipson L \& Wide P, "ECG analysis: a new approach in human identification", IEEE Trans. Instrum. Meas. Vol.50, No.3, (2001), pp.808-812.

[8] Kyoso M \& Uchiyama A, "Development of an ECG identification system", IEEE 23rd annual international conference of the Engineering in medicine and biology society, Vol.4, (2001), pp.3721-3723.

[9] Shen TW, Tompkins WJ \& Hu YH, "One-lead ECG for identity verification", IEEE 24th annual conference and the annual fall meeting of the biomedical engineering society embs/bmes, Engineering in medicine and biology, Vol.1, (2002), pp.62-63.

[10] Kim KS, Yoon TH, Lee JW, Kim DJ \& Koo HS, “A robust human identification by normalized time-domain features of electrocardiogram", IEEE 27th annual international conference of the Engineering in medicine and biology society, (2006), pp.1114-1117.

[11] Chan ADC, Hamdy MM, Badre A \& Badee V, "Wavelet distance measure for person identification using electrocardiograms", IEEE Trans. Instrum. Meas., Vol.57, No.2, (2008), pp.248-253.

[12] Agrafioti F \& Hatzinakos D, "ECG based recognition using second order statistics", IEEE Conference on Communication Networks and Services Research, (2008), pp.82-87.

[13] Safie SI, Soraghan JJ \& Petropoulakis L, "Electrocardiogram (ECG) biometric authentication using pulse active ratio (PAR)", IEEE Transactions on Information Forensics and Security, Vol.6, No.4, (2011), pp.1315-1322.

[14] Zhao Z, Yang L, Chen D \& Luo Y, "A human ecg identi_cation system based on ensemble empirical mode decomposition", Sensors, Vol.13, No.5, (2013), pp.6832-6864.

[15] Odinaka I, Lai PH, Kaplan AD, O'Sullivan JA, Sirevaag EJ, Kristjansson SD \& Rohrbaugh JW, "ECG biometrics: A robus short-time frequency analysis", IEEE international workshop on Information forensics and security (wifs), (2010), pp.1-6.

[16] Ross AA, Nandakumar K \& Jain AK, Handbook of multibiometrics. Springer Science \& Business Media, (2006).

[17] Senthilkumar R \& Gnanamurthy RK, "HANFIS: a new fast and robust approach for face recognition and facial image classification", Smart Innovations in Communication and Computational Sciences, (2019), pp.81-99.

[18] Raju K \& Srinivasa Rao Y, "A Novel Fusion Based Hybrid Approach For Face Recognition System", Journal of Theoretical 
and Applied Information Technology, Vol.95, No.9, (2017), pp.2054-2069.

[19] Amrutha B \& John PV, "Efficient Implementation on Human Face Recognition under Various Expressions using LoG, LBP and SVM", International Journal of Engineering Science and Computing, Vol.7, No.7, (2017), pp14052-14055.

[20] Ancy AV \& Devi M, "Aging Face Recognition Along with Personal Identification using Local Patterns Selection", International Journal of Engineering Science and Computing, Vol.7, No.5, (2017), pp.11396-11399.

[21] Azad AA, Hardi MM \& Zrar KA, "Wavelet-Local binary pattern based face recognition", International Journal of Computers \& Technology, Vol.16, No.1, (2017), pp.7552-7556.

[22] Sharadamani D \& Nagaraju C, "Face Recognition Using Gradient Derivative Local Binary Patterns", International Journal of Applied Engineering Research, Vol.12, No.7, (2017),

pp.1316-1323.

[23] Hamayun AK, "Feature Fusion and Classifier Ensemble Technique for Robust Face Recognition", Signal Processing: An International Journal (SPIJ), Vol.11, No.1, (2017), pp.1-15.

[24] Saloni D \& Nitika G, "A New Hybrid Approach on Face Detection and Recognition", International Journal of Advance Research, Ideas and Innovations in Technology, Vol.3, No.3, (2017), pp.485-492.

[25] Rupali SP, Sonali DP \& Sudeep DT, "Performance Evaluation of Fingerprint Trait Authentication System", International Conference on Intelligent Computing and Applications, Advances in Intelligent Systems and Computing, Vol.632, (2018), pp.143-151.

[26] Debnath B, Das JC \& De D, "Fingerprint authentication using QCA technology", IEEE Devices for Integrated Circuit (DevIC), (2017), pp.125-130.

[27] Patil PB \& Patil NN, "Fingerprint combination using extraction of minutiae position and orientation. IEEE International Conference on Emerging Trends in Engineering, Technology and Science (ICETETS), (2016), pp.1-6.

[28] Yang F, Paindavoine M, Abdi H \& Monopoli A, "Development of a fast panoramic face mosaicking and recognition system", Optical Engineering, Vol.44, No.8, (2005).

[29] Zhang YL, Yang J \& Wu HT, "A hybrid swipe fingerprint mosaicing scheme", International Conference on Audio-and VideoBased Biometric Person Authentication, (2005), pp.131-140.

[30] Marcialis GL, Roli F \& Didaci L, "Personal identity verification by serial fusion of fingerprint and face matchers", Pattern recognition, Vol.42, No.11, (2009), pp.2807-2817.

[31] Vatsa M, Singh R \& Noore A, "Unification of evidence-theoretic fusion algorithms: A case study in level-2 and level-3 fingerprint features", IEEE Trans. Syst. Man, Cybern. Part ASystems Humans, (2009), pp.47-56.

[32] Nanni L \& Lumini A, "Descriptors for image-based fingerprint matchers", Expert Systems with Applications, Vol.36, No.10, (2009), pp.12414-12422.

[33] Vatsa M, Singh R, Noore A \& Ross A, "On the dynamic selection of biometric fusion algorithms", IEEE Transactions on Information Forensics and Security, Vol.5, No.3, (2010), pp.470-479.

[34] Kumar A \& Shekhar S, "Personal identification using multibiometrics rank-level fusion", IEEE Transactions on Systems, Man and Cybernetics, Part C: Applications and Reviews, Vol.41, No.5, (2011), pp.743-752.

[35] Monwar MM \& Gavrilova M, "Markov chain model for multimodal biometric rank fusion", Signal, Image and Video Processing, Vol.7, No.1, (2013), pp.137-149.

[36] Nagar A, Nandakumar K \& Jain AK, "Multibiometric cryptosystems based on feature-level fusion", IEEE transactions on information forensics and security, Vol.7, No.1, (2012), pp.255268.

[37] Yang J \& Zhang X, "Feature-level fusion of fingerprint and fingervein for personal identification", Pattern Recognition Letters, Vol.33, No.5, (2012), pp.623-628.

[38] Zokaee S \& Faez K, "Human identification based on electrocardiogram and palmprint", International Journal of Electrical and Computer Engineering (IJECE), Vol.2, No.2, (2012), pp.261-266.

[39] Chan CH, Tahir MA, Kittler J \& Pietikäinen M, "Multiscale local phase quantization for robust component-based face recognition using kernel fusion of multiple descriptors", IEEE Transactions on Pattern Analysis and Machine Intelligence, Vol.35, No.5, (2013), pp.1164-1177.
[40] Huang Z, Liu Y, Li C, Yang M \& Chen L, "A robust face and ear based multimodal biometric system using sparse representation", Pattern Recognition, Vol.46, No.8, (2013), pp.2156-2168.

[41] Goswami G, Mittal P, Majumdar A, Vatsa M \& Singh R, "Group sparse representation based classification for multi-feature multimodal biometrics", Information Fusion, Vol.32, (2016), pp.3-12.

[42] Poh N, Ross A, Lee W \& Kittler J, "A user-specific and selective multimodal biometric fusion strategy by ranking subjects", Pattern Recognition, Vol.46, No.12, (2013), pp.3341-3357.

[43] Bhatt HS, Singh R \& Vatsa M, "On recognizing faces in videos using clustering-based re-ranking and fusion", IEEE Transactions on Information Forensics and Security, Vol.9, No.7, (2014), pp.1056-1068

[44] Zhang Z, Wang Y \& Zhang Z, "Face synthesis from low-resolution near-infrared to high-resolution visual light spectrum based on tensor analysis", Neurocomputing, Vol.140, (2014), pp.146-154

[45] Gogoi M \& Bhattacharyya DK, Proceedings of the Third International Conference on Soft Computing for Problem Solving, Springer India, New Delhi, (2014).

[46] Li C, Hu J, Pieprzyk J \& Susilo W, "A new biocryptosystemoriented security analysis framework and implementation of multibiometric cryptosystems based on decision level fusion", IEEE transactions on Information Forensics and Security, Vol.10, No.6, (2015), pp.1193-1206.

[47] Mehrotra H, Singh R, Vatsa M \& Majhi B, "Incremental granula relevance vector machine: A case study in multimodal biometrics", Pattern Recognition, Vol.56, (2016), pp.63-76.

[48] Hanmandlu M, "Multimodal biometric system built on the new entropy function for feature extraction and the Refined Scores as a classifier", Expert Systems with Applications, Vol.42, No.7, (2015), pp.3702-3723.

[49] Nguyen K, Denman S, Sridharan S \& Fookes C, "Score-level multibiometric fusion based on Dempster-Shafer theory incorporating uncertainty factors", IEEE Transactions on Human Machine Systems, Vol.45, No.1, (2015), pp.132-140.

[50] Bharadwaj S, Bhatt HS, Singh R, Vatsa M \& Noore A, "QFuse: Online learning framework for adaptive biometric system", Pattern Recognition, Vol.48, No.11, (2015), pp.3428-3439.

[51] Celik N, Manivannan N, Balachandran W \& Kosunalp S, "Multimodal biometrics for robust fusion systems using logic gates", Journal of Biometrics \& Biostatistics, Vol.6, No.1, (2015).

[52] Manjunathswamy BE, Appaji MA, Thriveni J, Venugopal KR \& Patnaik LM, "Article: Multimodal Biometric Authentication using ECG and Fingerprint", International Journal of Computer Applications, Vol.111, No.13, (2015), pp.33-39.

[53] Afshan A \& Isha V, "The Framework Design For Increasing Security Of Multi-Modal Biometric Authentication System With DNN", International Journal of Advanced Research in Computer Science, Vol.8, No.8, (2017), pp.343-348.

[54] Wang R, Han C, Wu Y \& Guo T, "Fingerprint classification based on depth neural network", arXiv preprint arXiv:1409.5188.. (2014), pp.1-14.

[55] Kouamo S \& Tangha C, "Fingerprint recognition with artificial neural networks: application to e-learning", Journal of Intelligent Learning Systems and Applications, Vol.8, No.02, (2016) pp.39-49.

[56] Gawande U, Golhar Y \& Hajari K, "Biometric-based security system: issues and challenges", Intelligent Techniques in Signa Processing for Multimedia Security, (2017), pp.151-176.

[57] Hambalık PMA, "Fingerprint recognition system using artificial neural network as feature extractor: design and performance evaluation", Tatra Mt. Math. Publ, Vol.67, (2016), pp.117-134.

[58] Xiaona X, Xiuqin P, Yue Z \& Qiumei P, "Research on kernel-based feature fusion algorithm in multimodal recognition", IEEE International Conference on Information Technology and Computer Science, (2009), pp.3-6.

[59] Mahoor MH, Cadavid S \& Abdel-Mottaleb M, "Multi-modal ear and face modeling and recognition", 16th IEEE International Conference on Image Processing (ICIP), (2009), pp.4137-4140

[60] Darwish AA, Abd Elghafar R \& Fawzi Ali A, "Multimodal Face and Ear Images", Journal of Computer Science, Vol.5, No.5, (2009), pp.374-379.

[61] Muhammad IR, Rubiyah Y \& Marzuki K, "Multimodal face and finger veins biometric authentication", Scientific Research and Essays, Vol.5, No.17, (2010), pp.2529-2534.

[62] Mohamed S, Noureddine D \& Noureddine G, "Face and Speech Based Multi-Modal Biometric Authentication", International 
Journal of Advanced Science and Technology, Vol.21, No.8, (2010), pp.41-46.

[63] Piotr D \& Andrzej C, "Human-Computer Interface Based on Visual Lip Movement and Gesture Recognition", International Journal of Computer Science and Applications, Vol.7, No.3, (2010), pp.124139.

[64] Linlin S, Li B \& Zzhen Ji," FPCODE: An efficient approach for multi-modal biometrics", International Journal of Pattern Recognition and Artificial Intelligence, Vol.25, No.2 (2011), pp. 273-286.

[65] Kawulok M \& Szymanek J, "Precise multi-level face detector for advanced analysis of facial images", IET Image Process., , Vol.6, No.2, (2012), pp.95-1031.

[66] Salloum R \& Kuo CCJ, "ECG-based biometrics using recurrent neural networks", IEEE International Conference on Acoustics, Speech and Signal Processing (ICASSP), (2017), pp.2062-2066.

[67] Raju, A S, and V Udayashankara, "Performance Evaluation of Multimodal Biometrics System", International Journal of Pure and Applied Mathematics, Vol.118, No.5, (2018), pp.367-382. 